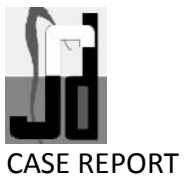

\title{
Fabrication of Interim Hollow Bulb Obturator Using Lost Salt Technique - A Case Report
}

\author{
Srinivasan J, Babu Rajan K, Smesh V
}

ABSTRACT: This report describes a simplified method for construction of an interim hollow bulb obturator for an acquired maxillary defect. Final impression was made with irreversible hydrocolloid and the master cast was blocked out with plaster. Wax up was done leaving the hollow bulb open after acrylization, the defect was filled with table salt and selfcure resin was used to cover the defect. Later a small hole was made and the table salt was washed off in water and the hole was also filled with self cure resin, The obturator was well retained in the patient's mouth and markedly improved hi s ability to speak and swallow-This technique proved to be a simple, quick, and cost-effective method for construction ofhollcw bulb Obturators for acquired maxillary defects.

Key words: Interim t) hturator, lost salt technique, Maxi//ofacia/proszhesis.

Rehabilitation of the patient with acquired or congenital maxillary defect is the most tedious job. The defect causes an oro-antral communication, making the speech and swallowing difficult due to the regurgitation of fluids. Disfigurement of face due to the loss of tissue, leads to severe psychological impairment in these patients." The maxillofacial prosthodontist, as a member of the surgical team, plans the design of the obturator right from the diagnostic phase before the surgery in consultation with the oral surgeon. He is able to aid in the recovery and rehabilitation of the maxillectomy patient by fabricating and placing a surgical obturator..$^{121}$ The immediate postoperative restoration of mastication, deglutition, and specch shortens the recovery time in the hospital and expedites the patient's return to the community as a functioning member.

The traditionol trootonont onausence for a motiont moniring

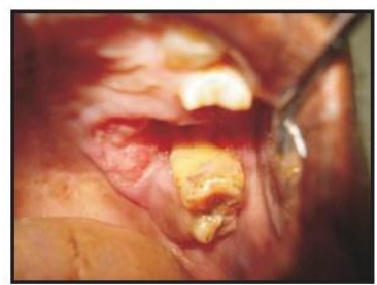

tigure-1 Squamous cell carcinoma of the palate.

The traditional treatment sequence for a patient requirmg a maxillectomy is the initial insertion of an immediate Figure-2 Diagnostic impression made with alginate.

surgical obturator at the time of surgery or soon thereafter and an interim obturator placed after initial healing of about 710 days after When the tissues are stabilized, after contraction and scarrmg (approximately 36 months) a definitive obturator is placed. This case -report describes a simple method for fabricati ng interim hol low bulb obturator prosthesis for a hemimaxillectomypatient.
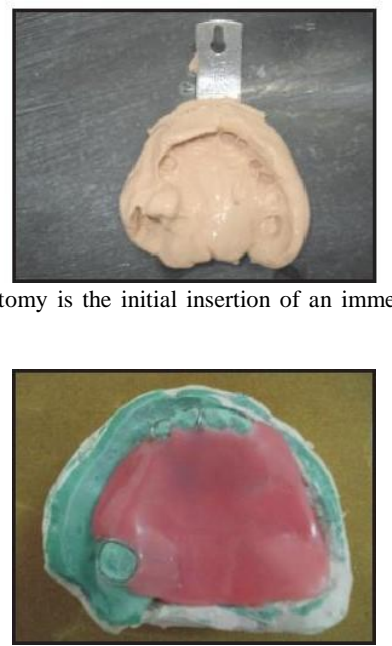


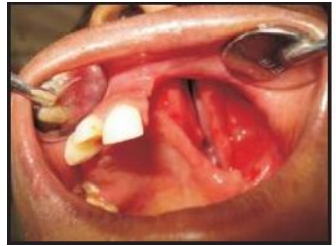

Figure_4 Surgical site post operatively after tfi0 weeks.

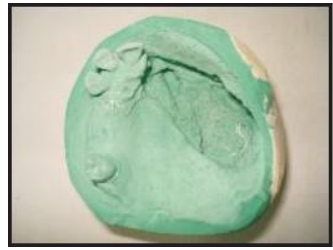

Figure-5 Final cast. Figure-IO Self cure acrylic resin used to cover the opening of the hollow bulb.

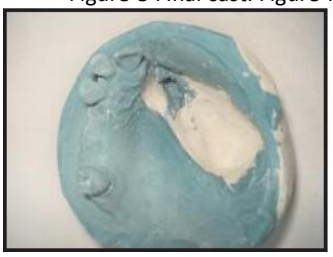

Fig111T-6 Unfavorable undercuts blocked out salt. with plaster- pumice.

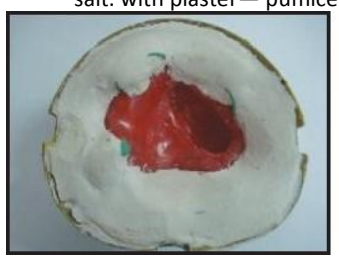

Figure-7 Wax up of final cast invested in dental nask.

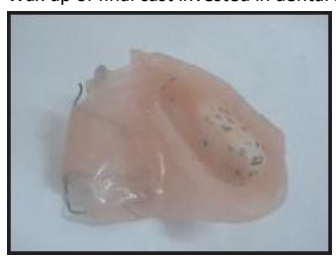

Figure-8 Open bulb interim obturator arter curing.

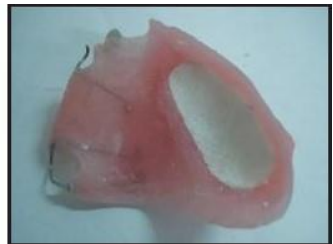

Figure-9 Table salt used to fill hollow bulb Of the interim obturator.
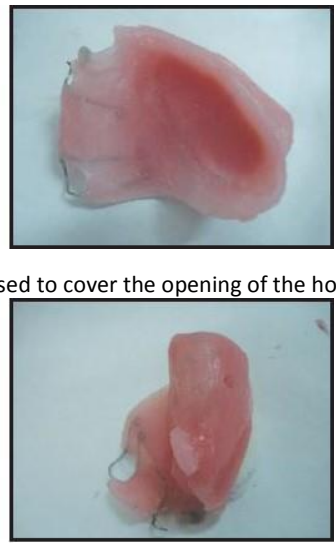

Figure_II Small hole made to dissolve and wash out the

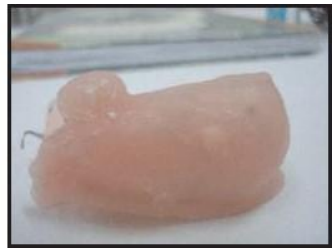

Figure-12 Smnll hole senled with self cure resin.

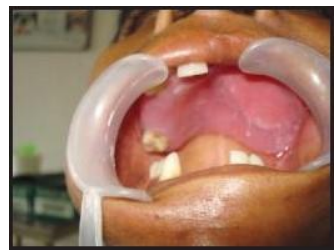

Figure-13 Final prosthesis ill place covering the defect completely. 


\section{CASE REPORT}

A female patient, aged 53yrs, reported to the Department of oral and maxillofacial surgery with a chief complaint of ulcer on the left side of the upper jaw for the past I year. On examination the patient was dentate with root stumps of 14, 15, 16 and missing 25, 26 An ulceroproliferative lesion with everted border was seen on the left side ofthehard palate. It was about $2 * 2 * 2 \mathrm{~cm}$, extending from the missing 25 region upto 28 region. It extended medially to the midline of palate (Fig I).

Radiographic evaluation revealed a radiolucent lesion in relation io the first molar extending up to the floor ofthe orbit. Biopsy was taken and the lesion was diagnosed as squamous cell carcinoma ofpalate. A hemimaxil lectomy was planned to remove the entire carcinovna and to place a subcutaneous skin graft.

The prosthetic design plan was to achieve a class I maxillary defect according to Mohammed Aramarty classification. 'A diagnostic impression was made with alginate reversible hydrocolloid, Zhermack, Italy.) (Fig 2) and the design of the obturator was planned on the diagnostic cast to provide a stable retentive interim obturator prosthesis. The surgical resection site was marked and removed for fabricating a surgical obturator (Fig-3). surgical obturator was secured using circumzygomatic wiring at the place after grafting. The immediate post operative period was uneventful and the s urgical obturator was removed after I $O$ days.

The surgical site showed good healing with less shrinkage (Fig-4). A dentulous, perforated, stainless steel stock tray size 4 (Jabbar \& Co) was selected and modified • with impression compound to cover the defect area. Dampened gauze was placed in the surgical site to cover the unwanted undercuts and to aid fävourable removal ofthc imp rcssion. The Irreversible hyd rocolloid (Zhermack, Italy) $\mathrm{W}$ as used to make the impres The impression was beaded and boxed and the fin al cast was poured in type III dental stone (Kalrock, Kalabhai International) (Fig-5). The unfavorable undercuts was blocked with pumice plaster mixture (Fig-6). Clasps were placed on teeth T3 and 18 to aid in retention of tlle prosthesis. The wax up of the defect was completed on the master cast. A large size dental flask was taken and reverse flasking was planned. The master cast was invest ed in the firstpour leaving the hollow bulb opening open (Fig-7). The second pour $w$ as used to fill the hollow wax u p. On dewaxing, heat cute acrylic resin packed and cured using the shon curing cycle. Deflasking was done and the hollow bulb was inspected (Fig-8). Table salt was used to fill the defect (Fig-9) and Autopolymerising acry lic resin used to cover the opening and create the hollow bulb (Fig- 10). On completion ofcuring, a small hole (FigII) was made on the base of the hollow bulb obturator and it was placed in waterto dissolve all the salt (Fig 12) The hollow bulb was washed with water in a syringe to remove the salt completely. The small hole was sealed with Autopolymerising acrylic resin. The obturator was finished and polished and inserted in the patient's mouth (Fig- 13).

The post insertion follow up was done after 24 hours, after three days and after one week. A review after every 10 to 14 days over the next two months period is needed. ${ }^{\text {LS }}$ The prosthesis will require revision due to tissue changes at the surgical site.

\section{mscuss10N}

The aim of the interim obturator prosthesis is to improve speech deglutition and to maintain oral hygiene to aid in tissue healing of the patient until a definitive $p$ rosthesis is constructed. An obturator can be made solid or hollow. The interim obturator is never kept half open as it is unhygienic andinvitcs infection The hollow bulb obtueator can be fabricated using two piece procedure or single piece procedure. ${ }^{[8,9]}$ An interim hollow bulb obturator has the advantage of being less weight to provide better retention and comfort to the patient and it also has a greater surface area for relining. ${ }^{\text {L") }}$ The technique used to fabricate the interim hollow bulb using table salt eliminates the making ofth e hollow hard shim which is made during the single piece procedure and two piece procedures for fabrication of hollow bulb obturator. This simple procedure ofmaking the hollow bulb reduces the I aboratory time considera bly to thirds.

\section{CONCLUSION}

This technique proved to bc a simple, quick, and cost effective method for construction of a hollow bu 15 obturator for acquired maxillary defects compared With the Other two teChniques of mak ing a hollow bulb obturator. REFFERENCE

1.Bhat V. A close up on obturators using magnets: Part II. J Indian Prosthodont Soc. 2006; 6:148-53.

2. Frame RT, King GE. A sulgical interim prosthesis. J Prosthet Dentl 981:45:108-

3. Curtis TA- Beumer J. Maxillofacial rehabilitationProsthodontic and surgical considerations St. Louis: Ishiyaku EuroAmerica 1996:225-84. 
4. Aramany MA. Basic principles of obturator design for partially edentulous patients. Part I: classification. J Prosthet Dent 1978;40:554-57.

S. Thomas D.Taylcr. Clinical maxillofacial prosthetics 2000 Quintessiance publ:92-3.

6. Kouyoumdjian JH, Chalian VA. An interim obturator
How to cite this article:

prosthesis with duplicated teeth and palate. J Prosthet Dent 1984; 52:560-2

7. Mihoko Haraguchi, Hitoshi Mukohyama, Hisashi Taniguchi. A simple method of fabricating an interim obturator prosthesis by duplicating the existing teeth

and palatal form. J Prosthet Dent 2006; 95:469-72.

8. Varoujan Joe BD. Maxillofacial prosthetics multi disciplinary practice 1st edition. William and Wilkins pub]: 13947.

9. Shaker K-T. A silnplified technique for construction of an interim obtuator for a bilateral total maxillcetomy

delZ•cl. Inl J Proslhodonl 2000;13: 166-68.

10. Rilo B, Dasilva JL, 1 , Mora MJ, Santana C. A hollow bulb interim obturator for maxillary resection. A case report. J Oral Rehabil. 2005; 32(3):23

\author{
Dr. Srinivasan Jayaraman \\ Reader \\ Dept of Prosthodontics. \\ Indira Gandhi Institute of Dental Sciences, \\ Sri Balaji Vidhyapecth \\ Pondy - Cudda101e Main Road. \\ Pillayarkupparn, Puducherry - 607402. \\ Email:srini rajee@iyahoo.co.in
}

SrinivasanJ, Babu Rajan K, Suresh V. Fabrication ofInterim Hollow Bulb Obturator Using Lost Salt Technique - A Case Report. Journal ofScientific Dentistry $2011 ;$ 1):37-40.

Source of Support: Nil, Conflict Ofl ntercst: $\mathrm{N}$ one declared 